\title{
O Paradigma Proprietário Da Enfiteuse No Ordenamento Jurídico Brasileiro: Entre Anacronismos E Resistências
}

\author{
Anderson Vieira * \\ Universiadade Estadual do Rio Grande do Norte, Programa de Pós-Graduação em Planejamento e \\ Dinâmicas Territoriais no Semiárido, Pau dos Ferros-RN, Brasil. \\ iD https://orcid.org/0000-0001-8999-0044 \\ Larissa da Silva Ferreira Alves ** \\ Universiadade Estadual do Rio Grande do Norte, Programa de Pós-Graduação em Planejamento e \\ Dinâmicas Territoriais no Semiárido, Pau dos Ferros-RN, Brasil.
}

Resumo: A enfiteuse, aforamento ou emprazamento, já se configurou no Brasil como única forma de concessão de terra após abolição do regime de sesmarias. Esse paradigma proprietário antecipa em anos a função social da propriedade, através das obrigações que consubstanciam sua natureza jurídica. Hoje, após existência conturbada, o instituto foi abolido no Código Civil de 2002, contudo, as relações já constituídas seguem sendo regidas pelas disposições do Código Civil de 1916 e esta é a realidade de centenas de cidades no Brasil. Assim, objetiva-se neste artigo analisar se a enfiteuse, não obstante sua extinção legislativa, é uma realidade concreta e impactante no ordenamento jurídico brasileiro. Para tanto, aplicou-se o método hipotético-dedutivo e como procedimentos metodológicos utilizou-se a revisão bibliográfica-documental e pesquisa jurisprudencial. Os dados utilizados foram gerados nos portais eletrônicos do STF, do STJ e em cada um dos 26 Tribunais de Justiça Estaduais, mais o Tribunal de Justiça do Distrito Federal. O principal resultado indica que a extinção legislativa da enfiteuse potencialmente aumentou a insegurança jurídica das relações e a inoficiosidade. Como conclusão, tem-se que a supressão do instituto do ordenamento jurídico brasileiro se configurou, de maneira preponderante, como uma escolha político-econômica e não a partir de uma inviabilidade jurídica.

Palavras-chave: Enfiteuse. Função Social da Propriedade. Segurança Jurídica.

* Mestrando em Planejamento e Dinâmicas Territoriais no Semiárido (PLANDITES) - UERN. E-mail: andersonhvieira@gmail.com

** Doutora em Geografia pela Universidade Federal do Ceará - UFC. Professora do Departamento de Geografia e Vice-Coordenadora do Programa de Pós-Graduação em Planejamento e Dinâmicas Territoriais no Semiárido (PLANDITES) da UERN. Presidente da Rede Internacional Interdisciplinar de Pesquisadores em Desenvolvimento de Territórios (Rede-TER). E-mail: larissa0185@gmail.com

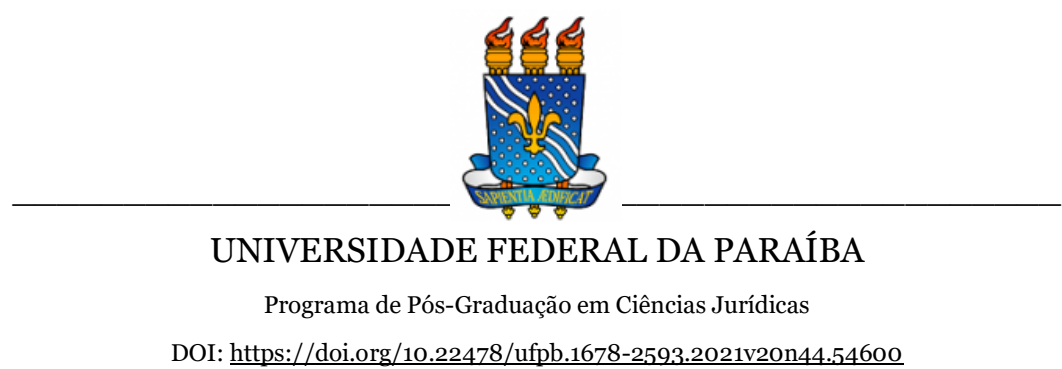




\title{
O Paradigma Proprietário Da Enfiteuse No Ordenamento Jurídico Brasileiro: Entre Anacronismos E Resistências
}

\author{
Anderson Vieira
}

Larissa da Silva Ferreira Alves

\section{INTRODUÇÃO}

O instituto da enfiteuse, aforamento ou emprazamento, já se configurou no Brasil como a única forma de concessão de terra, após a abolição do regime de sesmarias. Sua origem remonta ao século V a.C. no mundo grego e denota um forte caráter de direito público. Posteriormente, foi adotado em Roma e passou a ter uma configuração mais privada. Tanto sob o aspecto público como no aspecto privado, o instituto mantém seu caráter de funcionalização. Apesar de, na época em que surgiu, não ter sido pensado com esse fim, sua natureza jurídica sempre perpassou pelo o que hoje chama-se de "propriedade funcionalizada".

Pela sua lógica de divisão de domínios, a enfiteuse torna-se base da propriedade feudal e, não obstante sua origem milenar, esse paradigma jurídico continua vivo e apto a democratizar o acesso ao solo urbano em diversos ordenamentos jurídicos, tal como na Alemanha, França e Holanda. Para Grossi (2006, p.53), a divisão de domínio é "a tradução em termos jurídicos de uma mentalidade. É a mentalidade do primado do efetivo, é a mentalidade 'possessória' do alto medievo".

Após existência conturbada, o instituto da enfiteuse foi abolido no Código Civil de 2002. As relações já estabelecidas, antes da 
supressão legislativa, continuam sendo regidas pelo Código Civil de 1916. Assim, questiona-se: a enfiteuse, apesar da sua extinção legislativa, continua sendo uma realidade impactante no ordenamento jurídico brasileiro?

Para traçar possíveis respostas ao questionamento proposto, o presente artigo tem como objetivo analisar se a enfiteuse, não obstante sua extinção legislativa, é uma realidade concreta e impactante no ordenamento jurídico brasileiro. Para tanto, a pesquisa utilizou-se do método hipotético-dedutivo e como procedimentos metodológicos utilizou-se a revisão bibliográfica-documental e pesquisa jurisprudencial. A metodologia de análise dos dados foi qualitativa, através de análise de conteúdo (BARDIN, 2011).

Utilizou-se dados gerados nos portais eletrônicos do Supremo Tribunal Federal (STF), Superior Tribunal de Justiça (STJ) e em cada um dos 26 (vinte e seis) Tribunais de Justiça Estaduais, mais o Tribunal de Justiça do Distrito Federal. O recorte temporal da busca, em relação aos tribunais de justiça, diz respeito a todo o período disponível em cada sítio eletrônico até o ano de 2019, ou seja, os períodos irão variar de acordo com cada Tribunal, tendo uma média de 17 anos. Em relação ao STF, os dados dizem respeito aos últimos 84 anos (1936 a 2020) e no âmbito do STJ dos últimos 27 anos (1993 a 2020).

A relevância do tema do proposto neste manuscrito é expressa, sobretudo, pela necessidade de melhor compreender a natureza jurídica da enfiteuse, suas contingências, seu atual quadro de res(ex)istências no ordenamento jurídico brasileiro e a real possibilidade de democratizar o acesso ao solo para que possa ser feita uma necessária contribuição, ainda que seminal, para o debate público do direito à cidade.

Estruturalmente, além desta introdução, este artigo está assim organizado: a seção 2, que trata do delineamento conceitual do objeto de estudo; a seção 3, que destaca as contingências da enfiteuse e sua conexão com a democratização do acesso ao solo através da função social da propriedade; a seção 4, em que são destacados os aspectos 
O Paradigma Proprietário Da Enfiteuse No Ordenamento Jurídico Brasileiro...

legislativos da enfiteuse; e a seção 5, em que é traçado o quadro de recorrência da temática da enfiteuse no ordenamento jurídico brasileiro. Por último, na seção 6, traz-se algumas considerações finais, sugerindo que a abolição da enfiteuse está mais para uma escolha político-econômica do que para uma inviabilidade jurídica.

\section{DELINEAMENTO CONCEITUAL: O DESCOMPASSO ENTRE O LEGAL E O REAL}

A enfiteuse pode ser entendida como “[...] uma cisão no direito de propriedade, a mais profunda delas, pois rompe o 'domínio' em 'útil' e 'direto' ou eminente" (FONSECA, 2011, p.34). Concordando com Fonseca (2011, p.34), Aguiar (2014, p.146) esclarece que:

A enfiteuse deriva diretamente do arrendamento por prazo longo ou perpétuo de terras públicas a particulares, mediante a obrigação, por parte do adquirente (enfiteuta), de manter em bom estado o imóvel e efetuar o pagamento de uma pensão ou foro anual, certo e invariável, em numerário ou espécie, ao senhorio privado (proprietário). Este, através de um ato jurídico, intervivos ou de última vontade, atribui ao enfiteuta, em caráter perpétuo, o domínio útil e o pleno gozo do bem.

Nesse mesmo sentido, Aristi e Imbernón (2011, p. 139) definem enfiteuse como a concessão de direitos e prerrogativas proprietárias a um terceiro. Contudo, os autores não citam divisão no "domínio" do bem imóvel, mas sim na própria propriedade, em consonância com Fonseca (2016). Assim, para os autores, a relação enfiteutica é estabelecida "[...] quando um indivíduo dá a outro a chamada 'propriedade útil' de um imóvel, mantendo para si a chamada 'propriedade direta', em troca de uma pensão anual” (ARISTI; IMBERNÓN, 2011, p. 139).

Independente das particularidades conceituais de cada autor, um aspecto é comum: a enfiteuse caracteriza a multipropriedade. Em breves palavras, funciona da seguinte forma: o senhorio entrega, desde a fundação da povoação, lotes do solo urbano ou rural, aos enfiteutas 
que têm direito de posse, uso e gozo, inclusive, de alienar e transmitir por herança os lotes recebidos, com a eterna obrigação de pagar um módico foro ao senhorio, além das obrigações de conferir uma real utilidade da terra, as chamadas "melhorias".

Hunter (1803) relembra que a enfiteuse era atribuída aos arrendamentos longos ou perpétuos de terras tomadas em guerra concedidos pelo Estado romano. A renda dada por essa terra foi chamada de vectigal e a própria terra de vectigalis. As vantagens do arrendamento perpétuo, nestes termos, foram largamente utilizadas por corporações privadas, igrejas e entes públicos por aliviar a preocupação com a gestão das terras, mesmo que o arrendamento não representasse vultosos ganhos financeiros.

Van Erp e Akkermans (2012) diferenciam a enfiteuse do direito de usufruto por aquele ser de caráter potencialmente perpétuo, e, dessa forma, conferir mais segurança na relação estabelecida. Já Bocken e Bondt (2001, p.217), comentando sobre o contexto de inserção da enfiteuse na Bélgica em 1824, a partir da influência holandesa, destacam que os contratos enfitêuticos naquele território não podiam ter um caráter perpétuo, mas tão somente contratos de longa duração, com lapso temporal mínimo de 27 anos e máximo de 99 anos. Outro destaque bastante interessante, feito pelos autores, é quanto à obrigação financeira módica (quase simbólica) que a enfiteuse determina. Segundo eles, a

[...] enfiteuse é muito semelhante a um arrendamento, mas na verdade é um direito real e, como tal, pode ser imposta contra qualquer proprietário posterior do terreno. O contrato enfiteutico é sempre remunerado, mas a remuneração pode ser simbólica (digamos, um franco belga por ano), destinada apenas a obrigar o inquilino a reconhecer anualmente os direitos de propriedade do proprietário do terreno ou do edifício" (BOCKEN; BONDT, 2001, p. 217).

Scott (2001), em obra que analisa a história da propriedade em diversas épocas, cita importante aspecto da enfiteuse: o de privilegiar o direito à moradia. No trecho que segue, o autor destaca uma autorização concedida à Igreja Católica para dar em enfiteuse suas propriedades: 
Autoriza-se a Santíssima Igreja Principal, e todas as outras fundações religiosas, a arrendar sua propriedade por enfiteuse, desde que a duração do arrendamento seja limitada para a vida do enfiteuta e de dois de seus herdeiros, ou seja, seus filhos e netos, homens e mulheres; e essa propriedade reverterá para o marido ou para a esposa, se isso tiver sido expressamente declarado no contrato; caso contrário, não passará a nenhum outro herdeiro, mas será confinada unicamente às vidas daqueles que a receberam, quando não pertencerem a igrejas ou hospitais, ou mesmo a escravos rústicos ou suprimentos de grãos a serem arrendados, e não permitimos que uma alienação feita contrária a estas disposições tenha qualquer força (SCOTT, 2001, p.44).

O autor faz uma clara menção à limitação da possibilidade de transmissão, seja a título gratuito ou oneroso, previsão expressa de que o domínio iria ser transmitido do enfiteuta a seus herdeiros, e o título iria aproveitar ao marido e à mulher. É um reconhecimento do lar como um complexo de relações e interesses que devem ser considerados para preservação do direito à moradia dos integrantes desse núcleo familiar.

Essa conexão confere segurança jurídica da posse à família como um todo e pode se configurar como um avanço, em relação à tomada de decisões arbitrárias dentro do cenário da família patriarcal por parte do "chefe da família" que, frequentemente, são motivadas por violências de gênero. Sob este ponto, Yasun (2018), em estudo pioneiro que verificou a maior ou menor possibilidade de mulheres de uma cidade da Turquia receberem herança igualitária em relação aos homens, concluiu que a igualdade de gênero na detenção/titularidade de propriedades é fortemente obscurecida frente à igualdade de gênero na legislação. A argumentação da autora ganha relevo quando se observa os dados levantados por Cherif (2015) ao apontar que apenas $1 \%$ a $2 \%$ das terras titularizadas em todo o mundo pertencem a mulheres.

Não obstante os benefícios pontuados, as reformas liberais e sua onda desamortizadora em relação à propriedade, influenciou os Códigos Civis no ocidente e levou à supressão, em nível legislativo, do instituto da enfiteuse em diversos ordenamentos jurídicos, tal como na 
França, Holanda, Portugal e Argentina. Segundo Robilant (2014, p.385),

[...] a enfiteuse foi primeiro abandonada e depois reintroduzida devido a uma mudança nos valores associados à propriedade. Nos sistemas de propriedade contemporâneos, o risco de restabelecimento das hierarquias feudais parece menos real, ao passo que maior é a necessidade de permitir formas de propriedade que promovam o uso eficiente e "participativo" dos recursos.

A lógica proprietária funcionalista que orienta a constituição da enfiteuse era vista como resquício indesejável da feudalidade. Por isso, desconectada com a perspectiva privatista/patrimonialista que sustenta as legislações liberais, ou seja, a unificação de todos os poderes e prerrogativas proprietários em um único titular (FONSECA, 2016). Contudo, as dinâmicas sociais e urbanas mantiveram as relações proprietárias baseadas em arranjos complexos que se adequam, confortavelmente, aos pressupostos da enfiteuse, o que contribuiu para seu retorno, inclusive, nos países que outrora a aboliram, ainda que renovada ou com outros nomen iuris. A este respeito, Fonseca (2016, p.129) afirma que

[...] o retorno da enfiteuse na legislação francesa atual contrasta com a radicalidade do banimento do instituto no período revolucionário e mostra a resiliência e capacidade e adaptação da enfiteuse, mais ainda: a necessidade social do uso da propriedade pública e privada fora do mercado de imóveis. A política legislativa francesa torna-se assim emblemática para visualizar a complexidade da enfiteuse, cujas características ultrapassam as concreções e conceituações do direito positivo num determinado período da história do direito (FONSECA, 2016, p. 129)

A reinserção da enfiteuse em ordenamentos jurídicos que a aboliram indica que o instituto se conecta com o modelo liberal aplicado em quase todo o mundo e, muito embora não proporcione uma "revolução" na questão do acesso à terra, se configura como uma possibilidade de concretização da função social da propriedade e da própria cidade frente a um padrão fundiário rígido, segregador e pouco inclusivo.

No Brasil, o Código Civil de 1916 tinha um capítulo inteiro dedicado a esse instituto que regulamentava, desde a sua constituição até sua transmissão e as obrigações dos envolvidos na relação. Com o 
O Paradigma Proprietário Da Enfiteuse No Ordenamento Jurídico Brasileiro...

advento do Código Civil de 2002, o instituto foi extinto do códex e houve uma proibição de constituição de novas enfiteuses, o que representa um retrocesso do ponto de vista social, jurídico e teórico e atende a uma agenda político-econômica preponderantemente. Entretanto, as já existentes, quando do advento do Código Civil de 2002, seguem sendo reguladas pelas disposições do Código Civil de 1916. Importa deixar registrado que esta é a realidade de centenas de cidades brasileiras, tais como: Sousa-PB, Salgueiro-PE, Pau dos Ferros-RN, Alexandria-RN, Flores-PE, São José do Egito-PE, RecifePE, Olinda-PE, Paraty-RJ, Rio de Janeiro-RJ, Barueri-SP, Santana de Parnaíba-SP, Cruz das Posses-SP (PICCINATO; SALGADO, 2016), dentre outras.

Após analisar os elementos conceituais do instituto da enfiteuse, na próxima seção, será feita uma discussão sobre seus aspectos funcionalizantes como forma de destacar sua real possibilidade de contribuir na democratização do acesso à terra e privilegiar a função social da propriedade.

\section{CONTINGÊNCIAS E CONEXÕES: A ENFITEUSE ENQUANTO FORMA DE FUNCIONALIZAÇÃO DA PROPRIEDADE}

A discussão da enfiteuse, enquanto instituto complexo e multidisciplinar, perpassa também pela lógica dos Direitos Humanos, e essa conexão decorre diretamente do direito social à moradia, ou seja, da transmutação da propriedade exclusiva, excludente e absoluta para a propriedade enquanto direito social, transversal e funcionalizada. Fonseca (2016, p.39) afirma que é a passagem do "direito de", ao "direito à" propriedade. As principais características da enfiteuse, que justificam a garantia do direito social à moradia é sua perpetuidade, transmissibilidade, segurança jurídica da posse e preço acessível (MASTRODI; ALVES, 2017). Essas características são 
também o que contribui para uma sensível mudança no paradigma proprietário liberal.

As características citadas são expressas, por exemplo, ao longo das múltiplas e financeiramente acessíveis possibilidades de registro e documentação, em relação à detenção do domínio útil que é assegurado por meio da invariabilidade e modicidade dos percentuais pagos, tanto a título de foro (cerca de o,6\% do valor do terreno), obrigação paga anualmente pelo enfiteuta, quanto a título de laudêmio (cerca de 2,5\% do valor da alienação, caso outro valor não houver sido estipulado no título de aforamento), obrigação paga quando da transferência do domínio.

Para além das disposições mencionadas e da própria Constituição Federal de 1988, o Estatuto das Cidades, Lei no ${ }^{10.257}$ de 10 de julho de 2001, sustenta juridicamente a necessidade de garantir o direito social à moradia e mitigar o paradigma proprietário exclusivo, por intermédio da consolidação de quatro marcos jurídicos importantes: a noção de função social da propriedade (Art. 39); a gestão democrática da cidade (Art. 43); os instrumentos jurídicourbanísticos para a gestão do solo urbano (Art. 4을 e o direito de permanência dos ocupantes de terras para fins de moradia em assentamentos informais (Art. 42-A).

A opção legislativa de prever expressamente tais marcos jurídicos tem o objetivo claro de assegurar moradia digna e adequada a pessoas financeiramente e socialmente vulneráveis, por meio de outras formas de propriedade que não seja a propriedade franca, plena e absoluta, ou seja, onerosa e de difícil acesso. Uma posse segura é suficiente para atender a necessidades reais de moradia digna e adequada e mitigar o jogo de interesses do mercado imobiliário. Esse argumento reforça a importância da enfiteuse no espaço urbano, já que essa categoria jurídica se compatibiliza com o desenvolvimento das cidades que é fortemente marcado por ocupações espontâneas, informais e por arranjos proprietários plurifamiliares.

A capacidade de mutação do instituto da enfiteuse e a possibilidade de contratualmente alterar seus aspectos acessórios sem 
desnaturar seu cerne, qual seja, a funcionalização do bem (mediante a obrigação de "melhorias'), o torna apto e eficaz para atender à dinâmica urbana e corresponder às múltiplas necessidades dos atores que, mesmo sem o reconhecimento legislativo de outras formas de propriedade, estão a todo momento fazendo (re)arranjos entre si. Nesse sentido, Friendly (2020) destaca que não importa unicamente o nível de desenvolvimento do direito positivo e muito menos se este está ou não respondendo adequadamente às dinâmicas e necessidades dos sujeitos e das cidades. O fato é que a (re)produção do espaço urbano está sendo alterada a todo momento, de formas transversais e informais ao planejamento urbano "legal".

Para Fonseca (2016, p.68), as "melhorias" guardam "conteúdo semelhante ao da função social da propriedade”. Tepedino (2004) segue linha de entendimento semelhante, contudo, destaca que a função social da propriedade é muito mais extensa de forma que a enfiteuse não conseguiria sintetizar e não alcançaria todos os seus complexos elementos. Para Aronne (2013), a enfiteuse antecipa em séculos a função social da propriedade.

Outros autores, como Melo (2003, p. 182), enxergam a enfiteuse como "[...] um instituto anacrônico e absolutamente divorciado do paradigma da função social da propriedade", uma vez que confere direitos patrimoniais a indivíduo que não está dando destinação social à terra. Em consonância com Melo (2003, p. 182), para Miranda (1971, p.179) a enfiteuse é "[...] um dos cânceres da economia nacional, fruto de falsos títulos que, amparados pelos governos dóceis a exigências de poderosos, conseguiram incrustar-se nos registros de imóveis").

Tais concepções merecem ponderações tendo em vista que a natureza jurídica da enfiteuse prevê tão somente uma contrapartida financeira módica e anual, de forma que, nem de longe, tal contrapartida atende a aspectos de especulação imobiliária e acumulação. Quanto ao argumento de Miranda (1971), de captura da enfiteuse pelos interesses de classes detentoras do capital político e 
econômico, parece que há uma atribuição ao instituto de aspectos que fogem a sua natureza jurídica. Os objetivos para os quais o instituto da enfiteuse foi criado são claramente harmônicos a princípios socialmente inclusivos e democratizantes na questão da terra. Muito embora se compreenda que, no Brasil, ele legitima, em alguma medida, estruturas proprietárias, através da detenção de grandes extensões de terra, sobretudo de titularidade da igreja católica, contudo, propõe arranjos complexos por meio do desdobramento do domínio dessas terras que interessam à função social da propriedade e representa um avanço frente ao direito de propriedade inflexível e pouco inclusivo até hoje muito presente e impactante.

É sabido, ainda, que para a sua consecução, são necessários uma democracia e um Estado fortes o suficiente para sustentar uma forma de propriedade deliberativa, tal qual a enfiteuse, em que haja efetivamente participação popular nos processos decisórios e uma maior efetivação do direito à cidade e aos espaços. Em verdade, a inserção de obrigações no regime enfiteutico instrumentaliza a própria função social. Para Aronne (2001, p. 209) a

[...] análise histórica dos regimes de enfiteuse e superfície revela o cunho eminentemente funcionalizante da propriedade pública ou privada, desde a ratio de sua criação, em diferentes períodos históricos, atendendo a distintas necessidades sociais. Há íntima ligação entre a funcionalização de um instituto de direito real e sua obrigacionalização - pois a inserção de obrigações na titularidade é instrumento de função social e, consequentemente da dignidade da pessoa humana.

Há um claro descompasso entre o real e o legal, de modo que "[...] as contingências em torno da enfiteuse não cabem no direito positivo, apesar de ser um válido ponto de partida [...]" (FONSECA, 2016, p. 24).

Para além do que os códigos escritos podem expressar, o instituto é uma mentalidade proprietária, de forma que, para compreender como se deu a existência legislativa deste instituto no Direito Brasileiro, apresenta-se, na seção seguinte, algumas notas importantes que delineiam a conturbada (r)existência da enfiteuse em nosso ordenamento. 


\section{ENFITEUSE: ASPECTOS LEGISLATIVOS}

Seguindo a dinâmica das relações patrimoniais, por se constituir a relação de enfiteuse em direito real, exige-se a constituição de um título em registro público. Essa logística mostra-se adequada nas relações de propriedade, garantindo publicidade e segurança ao negócio jurídico celebrado num contexto bilateral. Contudo, ao vislumbrar uma coletividade socialmente vulnerável, que não pode arcar com os altos custos dos registros públicos no Brasil, torna-se conflituosa. Na enfiteuse, este aspecto pode ser amenizado pela possibilidade de registro público apenas do domínio direto, ou seja, as relações estabelecidas entre o titular do domínio direto (proprietário pleno) e seus foreiros se conformam adequadamente em documentações particulares (FONSECA, 2016).

$\mathrm{O}$ registro das enfiteuses tinha respaldo jurídico no art. 167, inciso 10, da Lei $\mathrm{n}^{0}$ 6.015/1973, que trata dos Registros Públicos. A Carta de Aforamento era o título de posse emitido pelo senhorio em favor do enfiteuta, tendo este a incumbência de registrá-la no cartório de registro de imóveis competente, para efeitos legais (FONSECA, 2016). Decorrente das dificuldades dos registros públicos no Brasil, a formalização das enfiteuses nem sempre acontecia, resultando numa “[...] irregular e descontínua cadeia de registros dos imóveis decorrentes do modelo de ocupação territorial no Brasil, das contingências decorrentes da espontaneidade, informalidade e, não raro, violência na ocupação inicial (FONSECA, 2016, p. 187).”

$\mathrm{O}$ que restava como alternativa frente à dificuldade do registro para atender a formalização era a inoficiosidade, utilizada pelos segmentos sem possibilidade de acesso formal à terra como forma de defesa contra os entraves. Assim, a documentação utilizada com o escopo de conferir um caráter mercantil à propriedade e individualizador ao proprietário era tida como eficaz estratégia de 
exclusão jurídica e também social (FONSECA, SILVA; ABRANTES, 2016).

Este é o retrato de várias porções do território brasileiro: ocupações espontâneas de grupos formados por populações vulneráveis, que detém a posse precária da terra, sem nenhuma segurança jurídica e, consequentemente, sem a possibilidade de moradia digna.

Um problema encontrado na gestão da enfiteuse privada é a natureza dos documentos de registro, resultante das diferenças de valores entre os tipos de domínio. O domínio útil mostra-se mais valioso que o direto, resultando na possibilidade de dois modos de documentação: um particular, emitido pelo senhorio e a escrituração pública obtida pelo foreiro. Fonseca $(2016$, p.199) afirma que o problema

[...] que atormenta os que lidam com a questão foreira são as lacunas documentais, descontinuidades de registros e transferências graciosas. É que vários atos e fatos jurídicos estão precária e tão somente gravados em instrumentos particulares. Uns da lavra dos senhorios diretários, outros dos transmitentes foreiros.

Há um receio, fruto de um condicionamento jurídico-social, expresso desde a Lei de Terras de 1850, quanto à validade de documentos particulares que não há respaldo jurídico, haja vista que os documentos particulares, atendidos aos requisitos legais contidos no art. 108 do Código Civil, são plenamente válidos. Assim, os documentos privados têm plena validade como registros particulares de negócios jurídicos, provocando efeito entre as partes (art. 221-CC), desde que regulem atos referentes a imóveis no valor de até 30 (trinta) salários mínimos (art. 108-CC).

É oportuno pontuar, ainda, que o documento particular não substitui o público, mas gera os efeitos garantidos na lei e se configura suficiente para garantir a devida segurança jurídica da posse, capaz de atender aos interesses das classes de menor renda da sociedade.

Fonseca (2016, p.117) faz uma análise dos discursos que permearam a promulgação da Constituição Federal de 1988. Verificou 
O Paradigma Proprietário Da Enfiteuse No Ordenamento Jurídico Brasileiro...

que, entre discursos abolicionistas e mantenedores, a resultante foi o artigo 49 do ato das disposições constitucionais transitórias (ADCT) que, nas palavras do autor, é um "híbrido jurídico que na prática pouco resolve e deixa para lei ordinária a responsabilidade de o fazê-lo”.

Nessa seara, o Código Civil de 2002, praticamente deixa de normatizar o instituto por completo, limitando-se a proibir novas constituições, o que a contrário senso acaba por aumentar a irregularidade fundiária e, aparentemente, tende a delinear uma sobreposição do primado da posse sobre a propriedade através do aumento da informalidade. Como consequência, resta um engessamento dos direitos reais num rol taxativo, o que fragiliza a dinâmica da propriedade como relação jurídica real, complexa e funcionalizada, e não responde satisfatoriamente à nova hermenêutica constitucional acerca da propriedade, sendo necessária sua repersonalização (ARONNE, 2001; FONSECA, 2016)

Analisando paralelamente os Códigos Civis antigo e atual, vê-se que o diploma mais novo substituiu a enfiteuse pelo direito de superfície. Contudo, a referida "substituição" merece ponderações. No quadro abaixo (quadro 01), é possível constatar quais institutos foram mantidos e quais foram suprimidos pelo Código Civil de 2002.

QUADRO 01: Comparativo entre institutos de Direitos Reais no CC de 2002 e no CC de 1916

\begin{tabular}{|l|l|}
\hline \multicolumn{1}{|c|}{ Art. 1.225 do CC de 2002 } & \multicolumn{1}{c|}{ Art. 674 do CC de 1916 } \\
\hline \multicolumn{1}{|c|}{ São direitos reais } & \multicolumn{1}{c|}{ Sãtos reais } \\
\hline São direitos reais & São direitos reais \\
\hline Propriedade & Propriedade \\
\hline Superfície & Emfiteuse. \\
\hline Servidões & Servidões \\
\hline Usufruto & Usofruto \\
\hline Uso & Uso \\
\hline Habitação & Habitação \\
\hline $\begin{array}{l}\text { O direito do promitente comprador do } \\
\text { imóvel }\end{array}$ & $\begin{array}{l}\text { As rendas expressamente constituídas } \\
\text { sobre imóveis }\end{array}$ \\
\hline Penhor & Penhor \\
\hline Anticrese & Anticrise \\
\hline Hipoteca & Hipoteca \\
\hline $\begin{array}{l}\text { A concessão de uso especial para fins de } \\
\text { moradia }\end{array}$ & Sem correspondente \\
\hline A concessão de direito real de uso & Sem correspondente \\
\hline A laje & Sem correspondente \\
\hline
\end{tabular}

FONTE: autoria própria (2020). 
A partir do quadro 01, é perceptível que praticamente todos os institutos de direito real encontrados no Código Civil de 1916 possuem correspondente no Código Civil de 2002, pelo menos do ponto de vista formal. As exceções ficam por conta das rendas expressamente constituídas sobre imóveis e da enfiteuse. A superfície, que aparece como pretensa substituta da enfiteuse, não consegue se adequar materialmente com esse instituto, tanto pela limitada quantidade de poderes concedidos ao superficiário, bem como pelas características de burocratização e onerosidade que atende a lógica de mercado.

Enquanto a enfiteuse tem características de perpetuidade e a obrigação anual do foreiro é módica, a superfície possui tempo determinado, sendo onerosa ou não e, ao seu termo final, o proprietário pode incorporar ao seu patrimônio, eventuais benfeitorias realizadas. A superfície mostra-se apta ao proveito da propriedade numa conotação de uso mais liberal do que social, num emprego lucrativo com a chancela das garantias formais previstas na lei civil.

Argumentação semelhante pode ser feita quanto às inserções da concessão de uso especial para fins de moradia, concessão de direito real de uso e a laje, que se configuram como importantes desdobramentos dos poderes proprietários. Porém, não representam a extensão e profundidade da enfiteuse, principalmente, no que tange à segurança habitacional proporcionada por meio da proteção da posse.

Os breves apontamentos feitos sobre os aspectos legislativos da enfiteuse, e sua conexão com a função social da propriedade, demonstram a importância e complexidade jurídica e social do instituto, de forma que vale a pena se questionar: esse paradigma proprietário, não obstante sua abolição legislativa no Código Civil de 2002, continua sendo tema recorrente no poder judiciário? É possível afirmar que a enfiteuse ainda é impactante nas cidades? É o que vamos discutir na próxima seção.

\section{A ENFITEUSE NO ORDENAMENTO JURÍDICO}

\section{BRASILEIRO}


Para o desenvolvimento deste artigo, foi realizada uma pesquisa pelos termos enfiteuse e aforamento no portal do STF, que retornou 353 (trezentos e cinquenta e três) acórdãos em um período de 84 (oitenta e quatro) anos, de 1936 a 2020, dos quais cerca de 59 (cinquenta e nove) tratam de resgate; 53 (quarenta e sete) da pena de comisso; 10 de anulação/nulidade da enfiteuse; 11 de competência legislativa em matéria de regimes enfitêuticos; 9 de desapropriação de domínio útil; 49 de foros (base de cálculo e cobrança) e 162 de outras matérias relativas a regimes enfitêuticos ou que pelo menos citam o termo enfiteuse ou aforamento em seus textos. As matérias foram esquematizadas no quadro 02 e a distribuição dos acórdãos estão expressos no gráfico 01, ao longo dos anos.

QUADRO 02: Ocorrência do termo enfiteuse e/ou aforamento nos acórdãos do Tribunais Superiores (STF)

\begin{tabular}{|l|c|}
\hline MATÉRIA & QUANT. DE ACÓRDÃOS \\
\hline Resgate & 59 \\
\hline Comisso & 53 \\
\hline Anulação/nulidade & 10 \\
\hline Competência legislativa & 11 \\
\hline Desapropriação de domínio útil & 9 \\
\hline Base de cálculo e cobrança de foros & 49 \\
\hline Outras & 162 \\
\hline Total & $\mathbf{3 5 3}$ \\
\hline \multicolumn{2}{|c|}{ Fonte: autoria própria (2020). } \\
\hline
\end{tabular}

GRÁFICO 01: Quantidade de acórdãos do STF que constam o termo enfiteuse ou aforamento nos últimos 80 anos

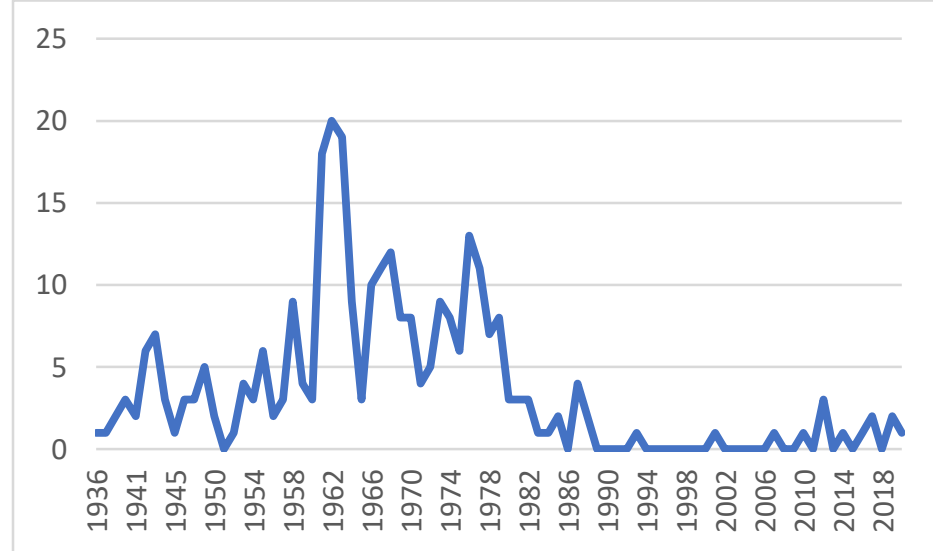

Fonte: autoria própria (2020)

Quando se analisa as matérias tratadas nos julgados, é relevante destacar que a maioria aborda a possibilidade de resgate das enfiteuses 
(59 resultados), isto é, que mediante o pagamento de $2,5 \%$ do valor do imóvel com suas benfeitorias, e mais 10 foros anuais (art. 693 do Código Civil de 1916), o foreiro tornar-se-ia o proprietário pleno do imóvel. Esses dados refletem a construção social, jurídica e histórica do exclusivismo proprietário e da absolutização da propriedade como forma de exclusão. Essa configuração é concretizada, sobretudo, pelos setores mais abastados da sociedade, ou seja, os atores que conseguem chegar até o STF com processos judiciais que, em geral, fazem parte de estamentos mais favorecidos por disporem de capital político e econômico.

Um caso curioso que, em alguma medida, serve para ilustrar o alegado é a Apelação Cível 9706/RS, julgada em 02 de junho de 1988, em que o governo da Itália objetivava adquirir, via usucapião, a propriedade de imóvel de titularidade do estado do Rio Grande do Sul, que o havia dado em aforamento. Naquela ocasião, o Supremo Tribunal Federal confirmou a sentença que extinguiu o processo sem resolução de mérito por impossibilidade jurídica do pedido.

A esses setores interessa deter o título exclusivo de propriedade para colocar esse imóvel dentro da dinâmica do mercado imobiliário e eventualmente lucrar. Não é razoável admitir que pequenas famílias, que visam resguardar seu direito de habitação e moradia, acessem a suprema corte constitucional, pagando altos valores a título de custas judiciais, para discutir o direito ao chamado "resgate”. A essas famílias, pertencentes a setores menos abastados, a mera posse é instrumento suficiente para atender seus interesses.

Outro aspecto que merece comentário é a respeito da quantidade de acórdãos (53), que versam sobre a pena de comisso. O comisso é uma sanção aplicada ao enfiteuta que deixa de cumprir com suas obrigações a título de pagamento de foro/laudêmio. Essa obrigação de pagamento é acessória à constituição da enfiteuse, já que a principal obrigação do foreiro é funcionalizar o imóvel, de forma que não é razoável admitir a resolução do contrato enfiteutico por não pagamento de foro/laudêmio de maneira direta, mas tão somente através de decisão judicial após regular processo de conhecimento. Tal 
entendimento, reiterado nos acórdãos do STF, privilegia aspectos de interesses sociais, reforça a perspectiva da enfiteuse enquanto instrumento da função social da propriedade (mesmo sem menção expressa nos acórdãos analisados), e protege juridicamente os foreiros, sobretudo, aqueles que compõe estratos mais vulneráveis da sociedade. Aronne (2001, p.251) corrobora a alegação ao afirmar que

\section{[...] a enfiteuse não visa remunerar o senhorio, enquanto eficácia direta do ato contratual constitutivo. Para tanto, existem diversas outras modalidades em nosso sistema jurídico. O gravame visa funcionalizar o bem. Daí a acessoriedade do foro; porém, ganha relevância a conduta do foreiro no seu exercício dominial.}

A grande controvérsia em relação a temática levou o STF editar as Súmulas $\mathrm{n}^{\circ} 122$ e 169, que deram uma releitura aos artigos 686 e 678 do Código Civil de 1916, ao pacificar que as obrigações de pagamento de foro e de laudêmio, por se caracterizarem como obrigações individuais, não podem se sobrepor a obrigação principal de dar utilidade ao imóvel concedido em enfiteuse.

Nenhum acórdão citou expressamente o termo "função social da propriedade”, essa ausência pode ser explicada pelo fato de que, a grande maioria dos acórdãos, cerca de 95\% (noventa e cinco por cento), foram prolatados antes da promulgação da Constituição de 1988, que positivou em nível constitucional, o referido princípio, tendo apenas 12 acórdãos sido prolatados após sua promulgação. Os números podem parecer inexpressivos quando se analisa o período de tempo em que os julgados foram proferidos, qual seja, de 1936 a 2020. Uma possível explicação para a "inexpressividade" dos julgados diz respeito à própria competência para julgamento do Supremo Tribunal Federal, notadamente, como corte constitucional, a ela cabe resguardar a Constituição Federal, julgando matérias que de maneira direta ou reflexa impactem no cumprimento de suas normas.

Quanto ao declínio dos acórdãos expresso no gráfico 01, virtualmente, pode representar aumento da inoficiosidade nas ocupações urbanas. As populações socialmente vulneráveis não podem arcar com os ônus dos registros e documentos públicos, típicos 
do regime de terras baseados na titularidade exclusiva. Esse cenário favorece o desenvolvimento de um largo regime de posses nas cidades baseados em arranjos complexos e informais.

Ao pesquisarmos os mesmos termos no portal do Superior Tribunal de Justiça, entre 1993 e 2020, a pesquisa retorna um total de 6.945 (seis mil, novecentos e quarenta e cinco) resultados, sendo 346 (trezentos e quarenta e seis) acórdãos; 6.581 (seis mil, quinhentos e oitenta e uma) decisões monocráticas e 18 (dezoito) informativos de jurisprudência, como mostra o quadro 03 .

QUADRO 03: Ocorrência do termo enfiteuse e/ou aforamento nos Tribunais Superiores (STJ)

\begin{tabular}{|l|c|}
\hline TIPO DE DECISÃO/ATO NORMATIVO & QUANTIDADE \\
\hline Acórdãos & 346 \\
\hline Decisões Monocráticas & 6.581 \\
\hline Informativos de Jurisprudência & 18 \\
\hline Total & $\mathbf{6 . 9 4 5}$ \\
\hline
\end{tabular}

FONTE: autoria própria (2020).

A expressiva quantidade de resultados retornados no âmbito do STJ é devido aos regimes enfitêuticos serem matéria de competência de julgamento típica deste tribunal, refletindo e reforçando a relevância jurídica e social, além da presença desse instituto na dinâmica urbana, de forma que, desconsiderar sua existência e optar por estruturar o planejamento urbano sob outras formas proprietárias, tal qual a propriedade plena - que atendem de maneira menos satisfatória a princípios de inclusão social e democratização de espaços - não parece ser a alternativa mais adequada.

Um importante aspecto a ser observado no âmbito do STJ é o grande número de acórdãos proferidos após a legislação extintiva da enfiteuse, notadamente 262 (duzentos e sessenta e dois) acórdãos. Cerca de 75\% (setenta e cinco por cento) do total analisado foram proferidos após a vigência do Código Civil de 2002. Esse dado indica que a opção legislativa de tão somente abolir a enfiteuse, sem regulamentá-la por inteiro, potencialmente gerou um quadro de insegurança jurídica e inoficiosidade. Ainda, relegou quase que 
O Paradigma Proprietário Da Enfiteuse No Ordenamento Jurídico Brasileiro...

inteiramente ao poder judiciário a tarefa de resolver os eventuais conflitos existentes nas relações enfitêuticas.

O quadro 04 abaixo representa a quantidade de acórdãos proferidos pelos Tribunais Estaduais do Brasil, que constam o termo enfiteuse e/ou aforamento. A pesquisa foi realizada no portal eletrônico de cada Tribunal de Justiça e os períodos compreendidos na tabela dizem respeito a todo o período disponível nos referidos portais. Para estabelecer o índice de conflitividade, foi feita uma relação entre a quantidade de acórdãos proferidos e o número de anos compreendido no período, a fim de se chegar a uma média em cada estado. Com isso, tendencialmente, identificar os estados em que a temática é decidida de maneira mais preponderante pelo poder judiciário.

QUADRO 04: Ocorrência do termo enfiteuse e/ou aforamento nos Tribunais estaduais (continua na próxima página)

\begin{tabular}{|c|c|c|c|c|}
\hline TRIBUNAL & $\begin{array}{c}\text { QUANTIDADE } \\
\text { DE } \\
\text { ACÓRDÃOS }\end{array}$ & $\begin{array}{c}\text { PERÍODO } \\
\text { COMPREENDIDO }\end{array}$ & $\begin{array}{c}\text { No } \\
\text { DE } \\
\text { ANOS }\end{array}$ & $\begin{array}{c}\text { ÍNDICE DE } \\
\text { CONFLITIVIDADE }\end{array}$ \\
\hline TJGO & 3 & $1994-2013$ & 20 & 0,15 \\
\hline TJMT & 3 & $2000-2014$ & 15 & 0,20 \\
\hline TJRR & 4 & $2006-2019$ & 14 & 0,29 \\
\hline TJTO & 5 & $2011-2018$ & 8 & 0,63 \\
\hline TJAC & 16 & $1998-2019$ & 22 & 0,73 \\
\hline TJSE & 4 & $2007-2010$ & 4 & 1,00 \\
\hline TJAM & 5 & $2014-2018$ & 5 & 1,00 \\
\hline TJSC & 18 & $2002-2018$ & 17 & 1,06 \\
\hline TJPI & 13 & $2010-2018$ & 9 & 1,44 \\
\hline TJAL & 36 & $1996-2019$ & 24 & 1,50 \\
\hline TJRN & 14 & $2009-2017$ & 9 & 1,56 \\
\hline TJDFT & 9 & $2014-2017$ & 4 & 2,25 \\
\hline TJRO & 280 & $1900-2019$ & 104 & 2,69 \\
\hline TJRS & 61 & $1998-2019$ & 22 & 2,77 \\
\hline TJES & 6 & 2017-2018 & 2 & 3,00 \\
\hline TJPR & 63 & $1999-2018$ & 20 & 3,15 \\
\hline TJPB & 21 & $2015-2019$ & 5 & 4,20 \\
\hline TJMA & 97 & $2000-2019$ & 20 & 4,85 \\
\hline TJPA & 75 & $2007-2019$ & 13 & 5,77 \\
\hline TJMS & 108 & $2002-2019$ & 18 & 6,00 \\
\hline TJRJ & 214 & $1988-2019$ & 32 & 6,69 \\
\hline TJPE & 197 & $1994-2019$ & 26 & 7,58 \\
\hline TJCE & 86 & $2013-2019$ & 7 & 12,29 \\
\hline TJBA & 191 & $2012-2019$ & 8 & 23,88 \\
\hline TJMG & 616 & $2000-2019$ & 20 & 30,80 \\
\hline TJSP & 661 & $2011-2019$ & 9 & 73,44 \\
\hline TJAP & - & - & - & - \\
\hline Total & 2806 & & & \\
\hline
\end{tabular}


Os resultados do quadro 04 dizem respeito somente a acórdãos, ou seja, decisões colegiadas, proferidas em segundo grau. Os números potencialmente tendem a ser bem mais expressivos que os aqui apresentados, haja vista que é preciso considerar as sentenças de primeira instância, que não estão inclusas no quadro.

Sobre os dados apresentados, o primeiro aspecto que merece relevo é a presença em si, da temática do instituto da enfiteuse em praticamente todos os tribunais estaduais do Brasil. O único estado sem o retorno de resultados foi o Amapá, o que não quer dizer que o instituto esteja ausente, mas tão somente, que eventuais conflitos não chegaram ao tribunal de justiça (em segunda instância) ou que, por questões logísticas e técnicas, os acórdãos deste tribunal não estão integralmente disponibilizados no portal. De uma forma ou de outra, os resultados expressam a forte presença da enfiteuse em todo território nacional, impactando na vida e nas relações proprietárias.

Um segundo aspecto interessante diz respeito a um argumento já desenvolvido neste artigo: a normativa abolicionista do Código Civil de 2002 não alterou a realidade fática de existência da enfiteuse nas cidades e deixou de normatizar toda a matéria, limitando-se a proibir novas constituições, restando ao judiciário regular esse quadro de informalidade gerado. Basta verificar que, dos 26 tribunais que retornaram resultados, 15 deles apresentaram resultados a partir do ano de 2002, ou seja, já na vigência do "novo" código civil e sua orientação supressiva da enfiteuse.

Vale lembrar que, as relações estabelecidas e os objetos dos conflitos que chegam até o judiciário são resolvidos a partir das normas constantes no Código Civil de 1916 e, caso não haja resolução dentre esses dispositivos, o magistrado decidirá a lide, utilizando de sua atividade criativa, da analogia, dos costumes e dos princípios gerais do direito, sempre visando os fins sociais a que a lei é dirigida, bem como das necessidades da coletividade, conforme determinam os artigos $4^{\circ}$ e $5^{\circ}$ do Decreto-lei $n^{\circ} 4.657$, de 4 de setembro de 1942 (Lei de Introdução as Normas do Direito Brasileiro). 
Esse quadro reforça a perspectiva de que o direito positivo, não obstante, ser um válido e necessário ponto de partida, não consegue atender e acompanhar a velocidade do desenvolvimento e estabelecimento das relações sociais, principalmente no que tange às relações proprietárias.

Quanto aos níveis de conflitividade, os índices estão dispostos de maneira crescente. O estado de Goiás apresenta o menor índice $(0,15)$, com apenas 03 (três) acórdãos proferidos em um período de 20 (vinte) anos. De outro lado, o estado de São Paulo desponta com o maior índice de conflitividade $(73,44)$ entre os tribunais estaduais do país, com mais de 600 (seiscentos) acórdãos proferidos em um período de 9 (nove) anos, seguidos pelos estados de Minas Gerais (30,80), Bahia $(23,88)$ e Ceará $(12,29)$. A maioria dos estados que retornaram resultados, cerca de 69\%, não tem um índice de conflitividade maior que 5,o (cinco), o que denota um baixo índice de conflitividade, ou seja, possivelmente as relações são estabelecidas e os eventuais conflitos resolvidos no campo do acordo entre os sujeitos e da informalidade.

Por último, foi realizada uma pesquisa no sistema de informações da Câmara dos Deputados, para verificar projetos de lei que tem como tema central a enfiteuse, emprazamento ou aforamento. A pesquisa retornou 9 (nove) resultados que estão organizados no quadro 05 por ano de proposição em ordem decrescente, sendo a $n^{0} 1$ a proposição mais recente (2019) e a $\mathrm{n}^{0} 9$ a proposição mais antiga (2000), desses, os projetos de lei que propõe extinção de regimes enfitêuticos e a concentração de todos os poderes proprietários no foreiro, em geral, tratam da enfiteuse pública, já os projetos que propõe modificações, tratam da enfiteuse privada.

Como poderia se explicar essa relação curiosa em que o "público" extingue-se e o "privado" modifica-se? As enfiteuses públicas, em geral, se localizam no litoral do país, são os chamados "terrenos de marinha", locais em que se encontram imóveis de altíssimos valores dentro do mercado imobiliário. Os projetos de lei 
extintivos dessas enfiteuses, provavelmente objetivam que essa porção territorial, já apropriada pelos setores mais privilegiados da sociedade, consigam aumentar ainda mais sua segurança jurídica, por meio da concentração de todos os poderes proprietários.

QUADRO 05: PL da Câmara dos Deputados que tem a enfiteuse como tema central

\begin{tabular}{|c|c|c|c|}
\hline No & PROPOSIÇÕES & $\begin{array}{c}\text { TIPO DE } \\
\text { ALTERAÇÃO }\end{array}$ & $\begin{array}{c}\text { TIPO DE } \\
\text { ENFITEUSE }\end{array}$ \\
\hline 1. & PL 807/2019 & Extingue & Pública \\
\hline 2. & PL 6834/2013 & Modifica & Privada \\
\hline 3. & PL 699/2011 & Extingue & Pública \\
\hline 4. & PL 192/2011 & Modifica & Pública e Privada \\
\hline 5. & PL 2692/2003 & Modifica & Privada \\
\hline 6. & PL 907/2003 & Modifica & Privada \\
\hline 7. & PL 7431/2002 & Modifica & Privada \\
\hline 8. & PL 7061/2002 & Modifica & Privada \\
\hline 9. & PL 3215/2000 & Extingue & Pública ou Privada \\
\hline
\end{tabular}

Fonte: autoria própria (2020).

A partir do quadro apresentado, faz-se alguns apontamentos. Primeiro, projetos de lei que visam a extinção da enfiteuse pública em benefício de sujeitos determinados ferem frontalmente a Constituição Federal de 1988, ao passo que desconsideram o princípio da impessoalidade, que deve orientar toda a gestão pública. Um segundo apontamento que se faz pertinente é sobre a própria natureza jurídica do instituto, isto é, a enfiteuse não objetiva beneficiar um sujeito em especifico, nem na modalidade privada e muito menos na modalidade pública, já que neste último caso, há uma conjunção de disposições constitucionais e infraconstitucionais que vedam tal prática. A existência de projetos com este viés extintivo do "público" só se explica face a um desconhecimento do ponto de vista técnico dos objetivos e da natureza jurídica a que o instituto da enfiteuse se presta ou frente as relações perniciosas público-privado no Brasil que, por vezes, orientam a ação pública (FONSECA; SILVA; ABRANTES, 2016). 
De base da propriedade feudal, a enfiteuse e sua orientação de divisão de domínios romperam séculos e tomaram conta da maioria dos ordenamentos jurídicos da Europa e das Américas. Apesar de hoje ser hóspede incômodo em muitas legislações liberais, o instituto já foi uma das principais formas de propriedade e continua vivo em vastas regiões pelo Brasil e pelo mundo. Os dados aqui apresentados reforçam essa realidade no Brasil e indicam a forte presença da enfiteuse em quase todo território brasileiro, repercutindo na vida, nas relações proprietárias e, consequentemente, no poder judiciário.

Assim, não obstante sua extinção legislativa, a enfiteuse continua sendo uma realidade concreta e impactante, demonstrando que não importa unicamente o nível de desenvolvimento do direito positivo e muito menos se este está ou não respondendo adequadamente às dinâmicas e às necessidades dos sujeitos e das cidades. O fato é que a (re)produção do espaço, especialmente do urbano, está sendo alterada a todo momento de formas transversais e informais.

A opção do legislador pátrio de deixar de regular inteiramente o instituto da enfiteuse, quando da elaboração do Código Civil de 2002, limitando-se a extingui-lo, gerou um quadro de insegurança jurídica e potencialmente aumento da inoficialidade das relações proprietárias sujeitas a contratos enfitêuticos e relegou ao poder judiciário, quase que inteiramente, a tarefa de mediar os conflitos que eventualmente aconteçam. A recorrência da temática da enfiteuse/aforamento nos julgados do Superior Tribunal de Justiça, pós vigência do Código Civil de 2002, corroboram essa afirmação.

A extinção também pode indicar um reforço à lógica da propriedade enquanto exclusão e afastamento da perspectiva de que, na mesma propriedade, possam coexistir usos múltiplos, por outros titulares que não sejam conflitantes ou excludentes ao uso do primeiro titular/possuidor, lógica basilar da relação enfitêutica. Nessa conjuntura, a opção por legislações extintivas se configura 
muito mais por uma escolha tão somente político-econômica, do que de fato jurídica.

Data de Submissão: 17/08/2020

Data de Aprovação: 10/10/2020

Processo de Avaliação: double blind peer review

Editor Geral: Jailton Macena de Araújo

Editor de Área: Fernando Joaquim Ferreira Maia

Assistente Editorial: Andréa Neiva Coelho

\section{REFERÊNCIAS}

AGUIAR, Fábio Gomes de. Registro Imobiliário e Notas. $1^{0}$ ed. São Paulo, SP: Clube de Autores, 2014.

ARISTI, Rafael Sánchez; IMBERNÓN, Nieves I. Moralejo. Property and Trust Law in Spain. Portland: Kluwer Law International, 2011.

ARONNE, Ricardo. Por uma nova hermenêutica dos direitos reais limitados. Das raízes aos fundamentos contemporâneos. Rio de Janeiro: Renovar, 2001.

ARONNE, Ricardo. Propriedade e Domínio: a teoria da autonomia: titularidades e direitos reais nos fractais do direito civil-constitucional. 2. ed., Vol. 1. Porto Alegre: Livraria do Advogado, 2013.

BARDIN, Laurence. Análise de conteúdo. São Paulo: Edições 70, 2011.

BOCKEN, Hubert; BONDT, Walter de. Introduction to Belgian

Law. 1. ed., Vol 1. Bruxelas: Kluwer Law International, 2001.

BRASIL. Código Civil de 2oo2. Disponível em:

http://www.planalto.gov.br/ccivil_03/leis/2002/L10406compilada. htm. Acesso: 24 jul. 2020.

BRASIL. Lei no 10.257, de 10 de julho de 2001. Disponível em: http://www.planalto.gov.br/ccivil_03/leis/leis_2001/l10257.htm. Acesso: 06 de out. de 2020.

CHERIF, Feryal M. Myths about women's rights: how, where, and why rights advance. $1^{\circ} \mathrm{ed}$. Oxford: Oxford University Press, 2015 . 
O Paradigma Proprietário Da Enfiteuse No Ordenamento Jurídico Brasileiro...

FONSECA, Paulo Henriques da; SILVA, Edjane Esmerina Dias da; ABRANTES, Elaine M. G. de. Poder Local, Doações de Imóveis Públicos e Direitos Territoriais em Mossoró, RN. Prim@ Facie, v. 15, n. 30, p. 01-31, 2016. Disponível em https://periodicos.ufpb.br/index.php/primafacie/article/view/33473 . Acesso em: 10 jun. 2020.

FONSECA, Paulo Henriques da. A enfiteuse e função social do solo urbano: a regularização local e popular. Anais do XX Congresso Nacional do Conselho Nacional de Pesquisa e PósGraduação em Direito, p. 1717-1741. Manaus, 2011. Disponível em: http://www.publicadireito.com.br/conpedi/manaus/arquivos/anais/ bh/paulo_henriques_da_fonseca.pdf. Acesso em: 10 jun. 2020.

FONSECA, Paulo Henriques da. Além do feudo e do burgo: a enfiteuse como instituto mutante, suas possibilidades e limites. Tese (Doutorado) - Universidade Federal de Pernambuco. Recife, 2o16. Disponível em: https://repositorio.ufpe.br/handle/123456789/18086. Acesso em 10 jun. 2020.

FRIENDLY, Abigail. The place of social citizenship and property rights in Brazil's 'Right to the city' debate. Social Policy and Society. Cambridge, v. 19, n. 02, p. 307-318, 2020. Disponível em: https://www.cambridge.org/core/journals/socialpolicy-and-society/article/place-of-social-citizenship-and-propertyrights-in-brazils-right-to-the-citydebate/8C205D6FED09C3DC712618C179326514. Acesso em: 10 jun. 2020.

FURTADO, Celso. Teoria e Política do Desenvolvimento Econômico. São Paulo: Abril Cultural, 1983.

GROSSI, Paolo. História da Propriedade e outros ensaios. Trad. Luiz Ernani Fritoli e Ricardo Marcelo Fonseca. Rio de Janeiro, São Paulo, Recife: Renovar, 2006.

HUNTER, William Alexander. A Systematic and Historical Exposition of Roman Law in the Order of a Code. 4. ed. Vol. 01. Londres: Sweet \& Maxwell, $\mathbf{1 8 0 3}$.

MASTRODI, Josué; ALVES, Ederson dos Santos. A segurança jurídica da posse como pressuposto do direito fundamental à moradia. Revista de Direito da Cidade. Rio de Janeiro, v. 9, n. 1, p. 27-49, jan. 2017. ISSN 2317-7721. DOI:

https://doi.org/10.12957/rdc.2017.23262. Disponível em: https://www.e- 
publicacoes.uerj.br/index.php/rdc/article/view/23262. Acesso em: 10 jun. 2020.

MELO, Marcos Aurélio Bezerra de. Anotações sobre os aspectos intertemporais do direito das coisas no Novo Código Civil. Revista EMERJ. Rio de Janeiro, v. 6, n. 24, p. 292-304, 2003. Disponível em: https://www.emerj.tjrj.jus.br/revistaemerj_online/edicoes/revista24 /revista24_292.pdf. Acesso em: 10 jun. 2020.

PICCINATO JUNIOR, Dirceu. SALGADO, Ivone. A conflituosa relação entre igreja e poder público municipal no gerenciamento da terra urbana - estudo de caso: Cruz das Posses, São Paulo. Revista Brasileira de Gestão Urbana. Curitiba, v. 8, n.2, 228-241. abril, 2016. Disponível em: https://dx.doi.org/10.1590/2175-3369.008.002.AO05. Acesso em: 10 jun. 2020.

PONTES DE MIRANDA, Francisco Cavalcante. Tratado de direito privado. 3. ed. v. 18. Rio de Janeiro: Borsoi, 1971.

ROBILANT, Anna di. Property and deliberation: The Numerus clausus principle, new property forms and new property values. The American Journal of Comparative Law. Oxford, v. 62, n. 02, p. 367-416, 2014. Disponível em:

https://www.jstor.org/stable/43668210?seq=. Acesso em: 10 jun. 2020.

SCOTT, Samuel Parsons. The Civil Law: Including the Twelve Tables, the Institutes of Gaius, the Rules of Ulpian, the Opinions of Paulus, the Enactments of Justinian, and the Constitutions of Leo. Union: The Lawbook Exchange, 2001.

TEPEDINO, Gustavo. Multipropriedade imobiliária. São Paulo: Saraiva, 1993.

VAN ERP, Sjef; AKKERMANS, Bram. Cases, Materials and Text on Property Law. 1 Ed. Vol. o1. Portland: Bloomsbury Publishing, 2012.

YASUN, Salih. Does education enable underprivileged women to achieve real equality in property rights? A case study of inheritance rights of women in Turkey. Women's Studies International Forum, Birmingham, v. 69, p. 100-114, 2018. DOI 10.1016/j.wsif.2018.05.013. Disponível em: http://searchebscohostcom.ez210.periodicos.capes.gov.br/login.aspx ?direct=true $\& \mathrm{db}=\mathrm{aph} \& \mathrm{AN}=130839419 \&$ site $=$ ehost-live. Acesso em: 10 jun. 2020. 
O Paradigma Proprietário Da Enfiteuse No Ordenamento Jurídico Brasileiro...

\title{
The Proprietary Paradigm Of The Emphyteusis In The Brazilian Legal System: Between Anachronisms And Resistances
}

\author{
Anderson Vieira
}

\section{Larissa da Silva Ferreira Alves}

\begin{abstract}
The emphyteusis, aforamento or emprazamento, has already been configured in Brazil as the only form of land concession after the abolition of the sesmarias regime. This proprietary paradigm anticipates in years the social function of property, through the obligations that substantiate its legal nature. Today, after a troubled existence, the institute was abolished in the Civil Code of 2002, however, the relations already constituted are still governed by the provisions of the Civil Code of 1916 and this is the reality of hundreds of cities in Brazil. Thus, the purpose of this article is to analyze whether the emphyteusis, notwithstanding its legislative extinction, is a concrete and impacting reality in the Brazilian legal system. For this, the hypothetical-deductive method was applied and as methodological procedures the bibliographic-documental review and jurisprudential research were used. The data used were generated in the electronic portals of the STF, the STJ and in each of the 26 State Courts of Justice, plus the Federal District Court of Justice. The main result indicates that the legislative extinction of the emphyteusis has potentially increased the legal insecurity of relations and the inofficiousness. As a conclusion, the suppression of the institute from the Brazilian legal system has been configured, in a preponderant way, as a political-economic choice and not from a legal unfeasibility.
\end{abstract}

Keywords: Emphyteusis. Social Function of the Property. Legal Security. 